\title{
Sponge cities and sustainable drainage systems: sharing best practice in China and the UK
}

\author{
Elizabeth Stewart ${ }^{1, a}$, Yuru Lin², Steven J. Cole ${ }^{1}$, Robert J. Moore ${ }^{1}$, Jijun Xu², Zhe Yuan ${ }^{2}$ and Deng Pan ${ }^{2}$ \\ ${ }^{1}$ UK Centre for Ecology \& Hydrology, Wallingford, Oxfordshire, OX10 8BB, United Kingdom \\ ${ }^{2}$ Changjiang River Scientific Research Institute, Wuhan 430010, China
}

\begin{abstract}
Flooding from rivers, surface water and the sea is a major hazard in many cities of the world and is expected to increase in the future due to climate change. With funding from the UK-China Urban Flooding Research Impact Programme, part of the UK-China Newton Fund, researchers and practitioners from both countries are collaborating on a project which focuses on surface water flooding and aims to enhance technical co-operation and knowledge-sharing in urban flood risk management. A comparison of current approaches to urban flood risk management in China and the UK is presented, and a case study of the benefits of Sponge City construction in the city of Wuhan, China is used by way of demonstration. Interventions to increase infiltration rates and on-site storage prove most effective for the 1-year return period, but have a more limited effect as flood event rarity increases. The paper discusses how similar results have been found in the UK for case studies of Sustainable Drainage Systems (SuDS), either installed in new urban developments or retrofitted in older ones. These studies also recognise the multiple benefits brought by the installation of green infrastructure, particularly in terms of community engagement and well-being.
\end{abstract}

\section{Introduction}

Urban flooding from multiple sources is a major hazard throughout the world. Flood risk is becoming more difficult to manage because of the size of the population exposed in urban settlements, and with the vulnerability of urban areas predicted to increase as rapid urbanisation continues (World Bank, 2012; Houston et al., 2011; UNDRR, 2019). Urban flooding is also likely to occur more frequently due to climate change, with the intensity of extreme rainfall events predicted to increase (IPCC, 2014). Against this backdrop, this paper focuses on current practice in surface water (or pluvial) flood management in urban areas of China and the UK. The approaches taken in the two countries to reduce the risk of surface water flooding through modification of flood pathways are compared and contrasted. A case study in China is used to demonstrate the effectiveness of Sponge City construction in flood hazard mitigation.

Surface water flooding occurs as a result of heavy rainfall which generates runoff that exceeds infiltration rates and local drainage capacity. Excess rainwater either ponds in surface depressions or flows over impermeable and saturated surfaces depending on the nature of the local micro-topography and drainage pathways. Typically, surface water flooding is caused by localised highintensity, short-duration rainfall events, making it difficult to predict in time and space. The incidence of surface water flooding does not have a direct link to the main river network. Although surface water flooding can occur in rural areas, for example as a result of agricultural practices that cause soil compaction (Wheater and Evans, 2009), its main impacts are experienced in towns and cities where paved surfaces replace permeable soils, generating rapid surface runoff and overwhelming drainage systems. In urban areas, the impacts of surface water flooding include inundation of domestic and commercial properties, particularly basements and ground floors, as well as the disruption of energy, water, communications and transport infrastructure, and public services such as schools and hospitals (Environment Agency, 2009).

Surface water flooding is an increasing problem in urban areas in both China and the UK. China has been experiencing rapid urbanisation since the 1980s with an estimated $60 \%$ of the population expected to be living in urban areas by 2020 (Cheshmehzangi, 2016). Its New-type Urbanisation Plan - a national strategy for 'humancentred' and 'environmentally friendly' urban development - was launched in 2014 in recognition of this growth. In large cities in China, the dominance of impermeable surfaces reduces the ability of the land surface to absorb large amounts of rainwater in a short time, thus triggering surface water floods (Dai et al., 2017). Many studies have demonstrated that rainfall patterns over China are changing and that the incidence of urban flooding is increasing due to an increase in the annual 
number of days of heavy rainfall exceeding $50 \mathrm{~mm} /$ day (Kundzewicz et al., 2019). This has been associated with increases in the incidence of high intensity storms of short duration and the enhancement of the urban heat island effect triggering convective rainfall. The immense disruption and destruction to citizens' lives, urban infrastructure and the economy have been particularly stark during recent floods in Beijing (2012), Ningbo (2013), Shenzhen (2014) and Wuhan (2016).

While there are obvious differences in scale, surface water flooding increasingly causes major disruption to communities and infrastructure throughout the UK. About 3.8 million properties are currently at risk of surface water flooding in England alone (Environment Agency, 2009): it is often considered to present a 'hidden risk' as those potentially affected may not be aware of it. In 2007, widespread surface water flooding resulted from outstanding late-spring and early-summer rainfall across England and Wales (Marsh, 2008). During the flooding over this extended period, 13 people died, 44,600 homes were flooded and the insurance industry paid out over $£ 3$ billion (Pitt, 2008). The unprecedented summer floods led to the 2008 Pitt Review, which in turn led to the Flood and Water Management Act 2010. This legislation provided clarity on the roles and responsibilities of the Environment Agency, local authorities, water and sewerage companies and others who manage flood risks. Other policy changes resulting from the Pitt Review included the recommendation to develop ways of working with natural processes to manage flood risk and using greener approaches to engineering.

Climate change projections suggest that the risk of high intensity rainfall leading to surface water flooding is likely to increase in both China (Kundzewicz et al., 2019) and the UK (Miller and Hutchins, 2017). While urban areas in the UK are generally considered to be particularly vulnerable to summer convective storms, a recent study of potential future changes in surface water flood hazard and impact in southern Britain found that the largest impacts on property are projected to occur in winter (Rudd et al., 2019).

\subsection{Background to the project}

This paper presents details of some of the activities being undertaken in a project entitled 'Enhancing China-UK technical co-operation, knowledge sharing and business opportunities in urban flood management and intelligent urban water network monitoring', funded through the UKChina Urban Flooding Research Impact Programme, delivered by the Royal Academy of Engineering within the UK-China Newton Fund. The project is led by the Changjiang River Scientific Research Institute (CRSRI) in Wuhan and involves the UK Centre for Ecology \& Hydrology (UKCEH), together with industry collaborators from China and the UK, and Chinese government representatives. The two-year project has a number of objectives:

- To establish a China-UK co-operation platform for the exchange of knowledge and expertise on urban flood management;
- Taking Wuhan as a demonstration area, to establish an intelligent monitoring system and regulation model;

- To enhance the flood monitoring and response capabilities of Wuhan City Water Authority and to identify optimal flood adaptation measures under different climate change scenarios.

The project is addressing these objectives through a programme of international workshops and field visits designed to share both experience of current practice in surface water flood risk management in urban areas and the underlying evidence base.

The research described in this paper contributes to the third objective using Wuhan as a case study. Further work on optimal adaptation to different climate change scenarios is planned to take place in the final stage of the project.

\section{Strategies for surface water flood management}

The source-pathway-receptor model provides a useful framework for understanding flood risk and developing management strategies. This study has focused on the pathways that lead to urban surface water flooding and the approaches taken to mitigate the effects in China and the UK.

Recent decades have seen the development of sustainable approaches to urban flood management in many countries of the world. A number of models for best practice have emerged including the Sponge City in China, Sustainable Drainage Systems (SuDS) in the UK, Low Impact Development (LID) in the USA and Water Sensitive Urban Development (WSUD) in Australia. All these approaches and related concepts - such as blue-green infrastructure and water-sensitive urban design - are based on the same principles of maintaining or replicating natural hydrological processes in urban catchments to manage floods, increase water quality, promote biodiversity and improve amenity.

\subsection{The Sponge City concept}

The Chinese Ministry of Housing and Urban-Rural Development (MOHURD) published guidelines for the construction of Sponge Cities in 2014 (MOHURD, 2014) and the Chinese Government formally initiated the 'Sponge City' programme the following year. This aimed to address the increasing incidence of urban flooding and waterlogging in Chinese cities (Dai et al., 2017; Griffiths et al., 2019). The concept of a Sponge City is based on the implementation of ecologically friendly alternatives to traditional flood defences and drainage systems which allow rainwater to be captured and surface runoff to permeate, so that flood risk is reduced, surface water quality is improved and water resources are conserved. Sponge City features include a number of low impact facilities - such as low-lying green space, permeable pavements, roof gardens and storage ponds - which are integrated with conventional drainage systems and water management infrastructure. Beyond reducing flood risk 
and improving water quality, these schemes can also have other ecological and health benefits too such as reducing temperatures and urban heat island effects (Lenth, 2016).

Thirty cities, including part of Wuhan, were designated Sponge Cities between 2015 and 2016. To guarantee the continuity of the programme and stability of funding, the policy adopted in China is top down, and the cities are directed to become 'sponges' to manage $70 \%$ of incident rainfall (Lashford et al., 2019). At present, the Sponge City programme focuses on the construction of demonstration areas where low impact drainage features are retrofitted and research activities are also concentrated.

\subsection{Sustainable Drainage Systems (SuDS)}

In the UK, similar approaches to the management of surface water that take account of water quantity, quality, biodiversity and amenity are collectively referred to as Sustainable Drainage Systems (SuDS). SuDS typically reduce flood risk in urban areas by managing runoff volumes and flow rates from hard surfaces, and such interventions are designed to maximise the opportunities and benefits that can be secured from surface water management (Woods Ballard et al., 2015). Thus, the philosophy behind sustainable drainage considers surface water as a valuable resource rather than a problem. SuDS mimic nature and typically manage rain close to where it falls. Examples include swales, green roofs, rain gardens, permeable pavements, trees and soakaways. These individual control measures can be linked together over a number of steps - the so-called 'management train' - to create an interconnected system designed to manage, treat and make best use of surface water from the point at which it falls as rain to the point at which it is discharged from the site (Woods Ballard et al., 2015).

The SuDS concept first emerged in the UK in the mid1990s, with the first design guidance for developers published in 2002 (Environment Agency, 2002). Since then, research, policy and guidance have been developed in the form of the CIRIA SuDS Manual (Woods Ballard et al., 2015), the Benefits Estimation (B£ST) tool (CIRIA, 2019) for assessing the benefits of blue-green infrastructure, and other web resources for developers and engineers. National planning policy across the UK requires local authorities to give priority to SuDS in planning applications, and the Environment Agency has developed a SuDS Research Framework, which comprises a set of operational needs and project ideas to steer and deliver collaborative research leading to increased resilience to flooding. While the importance of sustainable drainage is recognised in the planning of new developments in the $\mathrm{UK}$, there is also a need to encourage retrofitting of SuDS features to disconnect stormwater from the existing standard drainage network. Finally, ongoing maintenance of $\mathrm{SuDS}$ is essential for their optimal operation and this can cause issues related to ownership and costs.

\section{Case study: Wuhan, China}

A Sponge City Demonstration Area within the city of Wuhan has been the focus of a case study to simulate the runoff process and the drainage capacity of the pipe network both before and after the modification of the drainage system.

\subsection{Urban flood risk in Wuhan}

Wuhan is a large city in China which has a high population (about 11 million people in 2020), is experiencing rapid urban development and is extremely vulnerable to urban flooding. Located in the middle reaches of the Yangtze River, Wuhan is the capital of Hubei province and its low-lying position at the confluence of the Yangtze and Han rivers means that it has always been prone to floods, especially in the summer months. Once known as "the city of a hundred lakes" (there are 166 lakes and 163 rivers in the city), the abundance of water has created opportunities for development, although at the same time it has brought problems such as waterlogging and pollution. The climate of Wuhan is characterised by high intensity, long duration rainfall. Published statistics report a total of 136 rainstorms (of more than $50 \mathrm{~mm}$ /day) in Wuhan since 1959, including 30 heavy rainstorms of over $100 \mathrm{~mm} /$ day (CRSRI, 2019). Fourteen people died in the flood disaster of July 2016, roads in the city were paralysed and the drainage system was severely challenged.

Wuhan was one of the first tranche of designated Sponge Cities and, while large investments in urban floodrelated infrastructure have been made, there is still a lack of effective monitoring and management of urban floods. This project seeks to help address this shortcoming through a China-UK collaborative initiative on sharing best practice.

\subsection{Overview of study area}

The study area is part of the South Trunk Canal Area, which is located in the southern part of the Qingshan District of Wuhan, in the middle reach of the Gangxi drainage system. The Yangtze River runs along the northwest edge of the area (Figure 1).

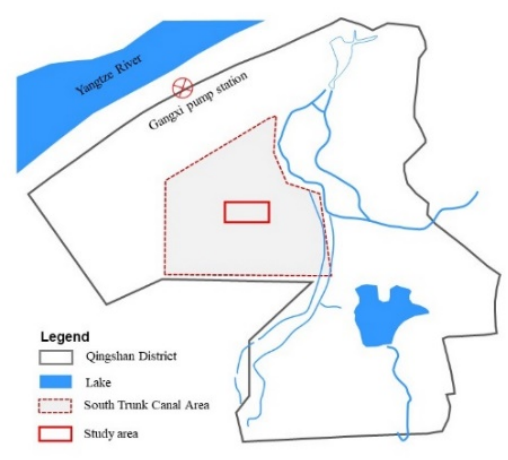

Figure 1. Location of the study area.

The ground elevation of the Gangxi drainage system is between 21 and $25 \mathrm{~m}$ and the water level of the Yangtze River fluctuates from $14 \mathrm{~m}$ to $28 \mathrm{~m}$. Before the construction of the Sponge City, rainwater was discharged into the Yangtze River by gravity during the dry season, 
and by pumping during the rainy season. Urban flood control relied mainly on flood defence projects and a drainage system implemented by central and local governments. Following Sponge City construction, rainwater is collected and stored by specially designed interventions, then transferred to the Gangxi Pumping Station, and finally discharged into the Yangtze River.

Field observation was used to classify land use in the study area into four major categories of green space, roads, artificial lake and paved areas (squares). The total area covers $51,420 \mathrm{~m}^{2}$, including $42,631 \mathrm{~m}^{2}$ of green space, $3,444 \mathrm{~m}^{2}$ of water bodies and $5,345 \mathrm{~m}^{2}$ of roads and paved areas (Figure 2).

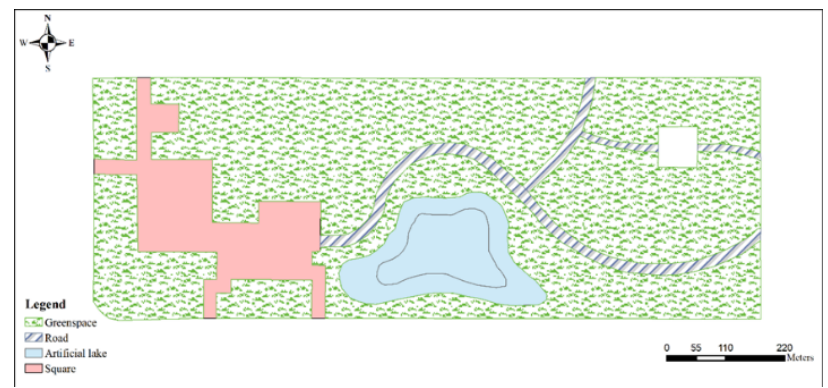

Figure 2. Land use of study area.

\subsection{Model set-up}

Using reference data including surface elevation, land use and the pipe network, the Storm Water Management Model (SWMM: EPA, 2016) was set up to simulate runoff across the study area, which was sub-divided into 45 subcatchments, 36 conduits, 38 junctions and 8 outlets (Figure 3). The SWMM model was selected as it is widely used throughout the world for planning, analysis and design of stormwater runoff facilities in urban areas and is able to simulate the operation of green infrastructure in increasing infiltration and reducing surface runoff.

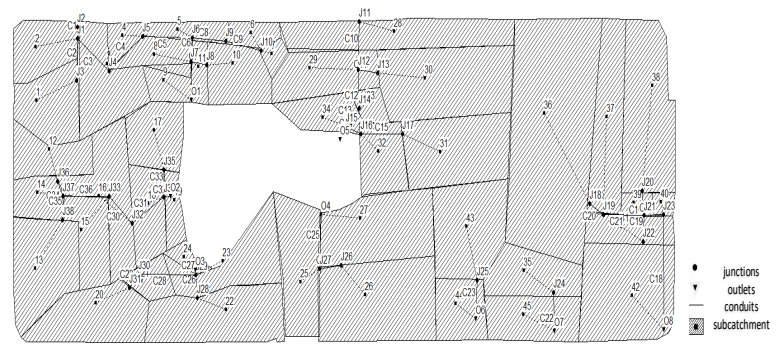

Figure 3. Generalised model of the study area.

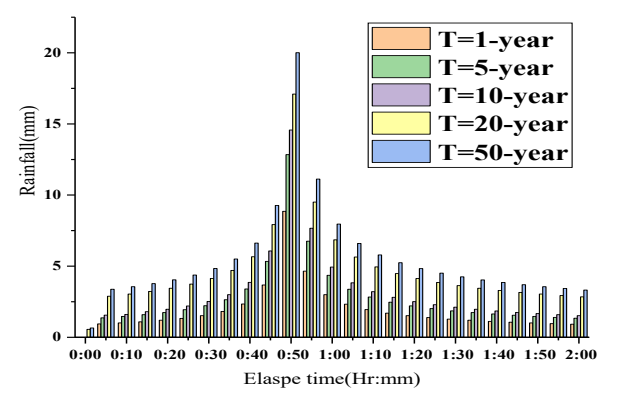

Figure 4. Design storm hyetographs for the 2-hour duration.
For the analysis of design events, short-duration design storms were constructed for Wuhan for a range of return periods using a local standard method and the Chicago storm hyetograph model (Keifer and Chu, 1957) was used to fit design storm profiles. Figure 4 shows 2-hour design hyetographs for Wuhan using a time-step of 5 minutes for different return periods.

Annual precipitation records from Wuhan Central Meteorological Observatory for 2011 to 2018 indicate that the annual precipitation fluctuates between 700 and 1800 $\mathrm{mm}$. Considering this period of record, 2013, 2018 and 2012 were selected as typical horizon years, representing years of high flow, medium flow and low flow, respectively (average annual precipitation was 1398.4, 1025.3 and $725.1 \mathrm{~mm}$, respectively).

\subsection{Results for representative years}

Runoff rates and volumes, and the drainage capacity of the pipe network, were simulated for the representative years both before and after the construction of the Sponge City.

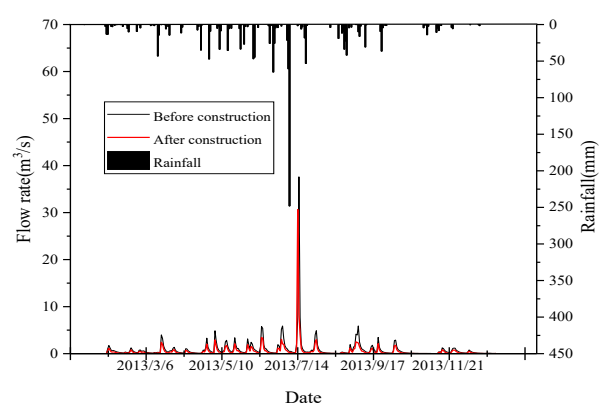

(a) High flow year

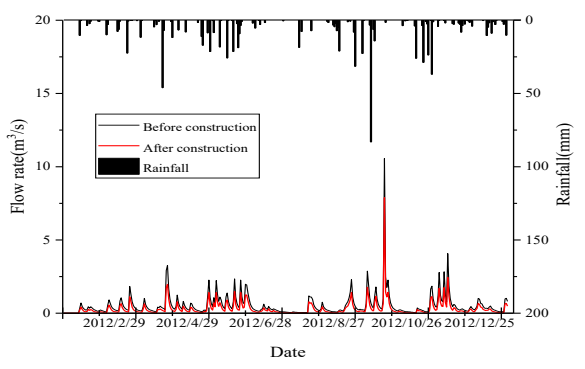

(b) Medium flow year

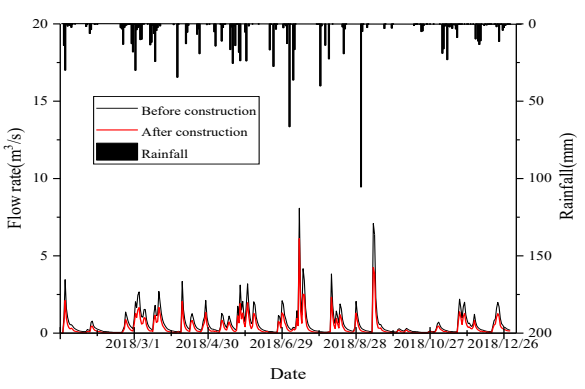

(c) Low flow year

Figure 5. Comparison of runoff rates before and after Sponge City construction. 


\section{Runoff reduction rate}

Figure 5 illustrates the reduction in runoff rate achieved as a result of constructing the Sponge City features for the representative years.

A summary of the reductions in flow rates and volumes achieved by the Sponge City drainage features are shown in Table 1. Taking the high flow year as an example, the average flow rate was reduced from 0.82 to $0.50 \mathrm{~m}^{3} / \mathrm{s}$, with a reduction rate of $39.0 \%$. Runoff volume for the high flow year was reduced from 25.70 to $15.6010^{6} \mathrm{~m}^{3}$, representing a reduction of $39.3 \%$. Similar reduction rates were found in the medium and low flow years

The conclusion from this analysis is that Sponge City construction has effectively reduced the average flow rate and runoff volume by approximately $40 \%$ in the study area for the three representative years.

\begin{tabular}{|c|c|c|c|c|}
\hline & & Before & After & $\begin{array}{c}\text { Reduction } \\
\text { rate }(\%)\end{array}$ \\
\hline \multirow{3}{*}{$\begin{array}{l}\text { Flow } \\
\left(\mathbf{m}^{3} / \mathbf{s}\right)\end{array}$} & $\begin{array}{c}\text { High } \\
\text { flow year }\end{array}$ & 0.82 & 0.50 & 39.0 \\
\hline & $\begin{array}{l}\text { Medium } \\
\text { flow year }\end{array}$ & 0.64 & 0.38 & 40.6 \\
\hline & $\begin{array}{c}\text { Low } \\
\text { flow year }\end{array}$ & 0.53 & 0.31 & 41.5 \\
\hline \multirow{3}{*}{$\begin{array}{l}\text { Runoff } \\
\left(1^{6} \mathrm{~m}^{3}\right)\end{array}$} & $\begin{array}{c}\text { High } \\
\text { flow year }\end{array}$ & 25.70 & 15.60 & 39.3 \\
\hline & $\begin{array}{l}\text { Medium } \\
\text { flow year }\end{array}$ & 20.20 & 12.01 & 40.5 \\
\hline & $\begin{array}{c}\text { Low } \\
\text { flow year }\end{array}$ & 39.30 & 40.54 & 42.3 \\
\hline
\end{tabular}

Table 1. Comparison of flow rates and runoff volumes after construction of the Sponge City

\section{Drainage capacity of pipe networks}

The effect of Sponge City features on the drainage capacity of the study area was further investigated by analysing overflows and pipe overloading of nodes (Figure 6 and Table 2). Taking the high flow year as an example, the number of nodes with overflows is reduced from 9 to 3 by the Sponge City, representing a reduction rate of $66.7 \%$; the number of nodes with pipe overloading is reduced from 26 to 16 , a reduction rate of $38.5 \%$. Further reductions were simulated for the medium and low flow years (see Table 2), illustrating how Sponge City construction has effectively improved the drainage capacity in the study area.

\begin{tabular}{|c|c|c|c|c|}
\hline & & Before & After & $\begin{array}{c}\text { Reduction rate } \\
(\%)\end{array}$ \\
\hline \multirow{3}{*}{$\begin{array}{l}\text { Numbers } \\
\text { of nodes } \\
\text { with } \\
\text { overflows }\end{array}$} & $\begin{array}{l}\text { High } \\
\text { flow year }\end{array}$ & 9 & 3 & 66.7 \\
\hline & $\begin{array}{l}\text { Medium } \\
\text { flow year }\end{array}$ & 4 & 0 & 100.0 \\
\hline & $\begin{array}{c}\text { Low } \\
\text { flow year }\end{array}$ & 0 & 0 & - \\
\hline \multirow{3}{*}{$\begin{array}{c}\text { Numbers } \\
\text { of nodes } \\
\text { with pipe } \\
\text { overloads }\end{array}$} & $\begin{array}{c}\text { High } \\
\text { flow year }\end{array}$ & 26 & 16 & 38.5 \\
\hline & $\begin{array}{c}\text { Medium } \\
\text { flow year }\end{array}$ & 26 & 7 & 73.1 \\
\hline & $\begin{array}{c}\text { Low } \\
\text { flow year }\end{array}$ & 8 & 4 & 50.0 \\
\hline
\end{tabular}

Table 2. Comparison of nodes with overflows and pipe overloading after construction of the Sponge City.

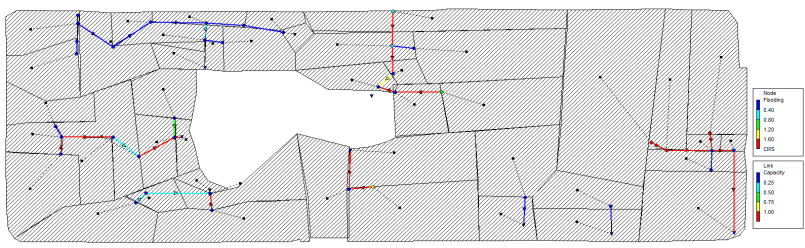

(a) High Flow Year (7 July 2013)

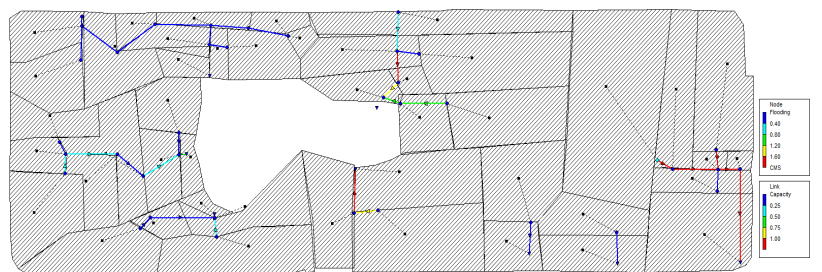

(b) Medium Flow Year (2 September 2018)

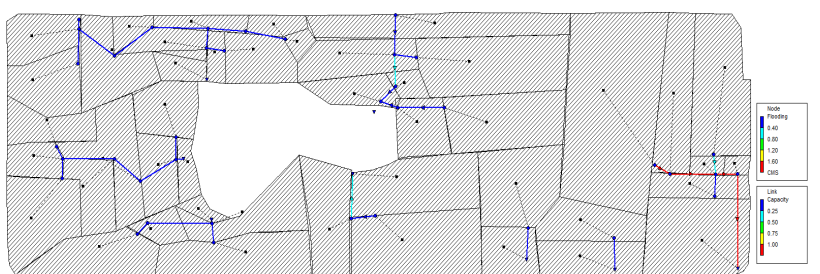

(c) Low Flow Year (9 September 2012)

Figure 6. Drainage capacity of pipe networks after Sponge City construction

\subsection{Results for different return periods}

\section{Runoff reduction rate}

The analysis of runoff processes before and after Sponge City construction was repeated for three design events of 1-, 5- and 10-year return period and the results are presented in Figure 7 and Table 3. Taking the 1-year event as an example, the Sponge City reduces runoff substantially: peak flow is reduced from 9.68 to $7.55 \mathrm{~m}^{3} / \mathrm{s}$, a reduction rate of $22 \%$, and total runoff is reduced from 5.15 to $3.8710^{5} \mathrm{~m}^{3}$, a reduction rate of $24.9 \%$. Smaller percentage reductions in peak flow and runoff volume were found for the 5- and 10-year return period events, suggesting that the beneficial effects of Sponge City interventions have a more limited effect as flood event rarity increases.

\begin{tabular}{|c|c|c|c|c|c|}
\hline \multicolumn{2}{|c|}{$\begin{array}{l}\text { Return period } \\
\qquad(\mathrm{P} / \mathrm{a})\end{array}$} & $\begin{array}{c}\text { Peak } \\
\text { flow } \\
\left(\mathrm{m}^{3} / \mathrm{s}\right)\end{array}$ & $\begin{array}{c}\text { Reduc- } \\
\text { tion rate } \\
(\%)\end{array}$ & $\begin{array}{c}\text { Total } \\
\text { runoff } \\
10^{5} \mathrm{~m}^{3} \\
\end{array}$ & $\begin{array}{l}\text { Reduction } \\
\text { rate }(\%)\end{array}$ \\
\hline \multirow{2}{*}{1} & Before & 9.68 & \multirow{2}{*}{22.0} & 5.15 & \multirow{2}{*}{24.9} \\
\hline & After & 7.55 & & 3.87 & \\
\hline \multirow{2}{*}{5} & Before & 16.90 & \multirow{2}{*}{5.3} & 7.08 & \multirow{2}{*}{5.2} \\
\hline & After & 16.00 & & 6.71 & \\
\hline \multirow{2}{*}{10} & Before & 20.45 & \multirow{2}{*}{5.3} & 8.18 & \multirow{2}{*}{5.5} \\
\hline & After & 19.36 & & 7.73 & \\
\hline
\end{tabular}

Table 3. Comparison of runoff in different return periods after Sponge City construction 

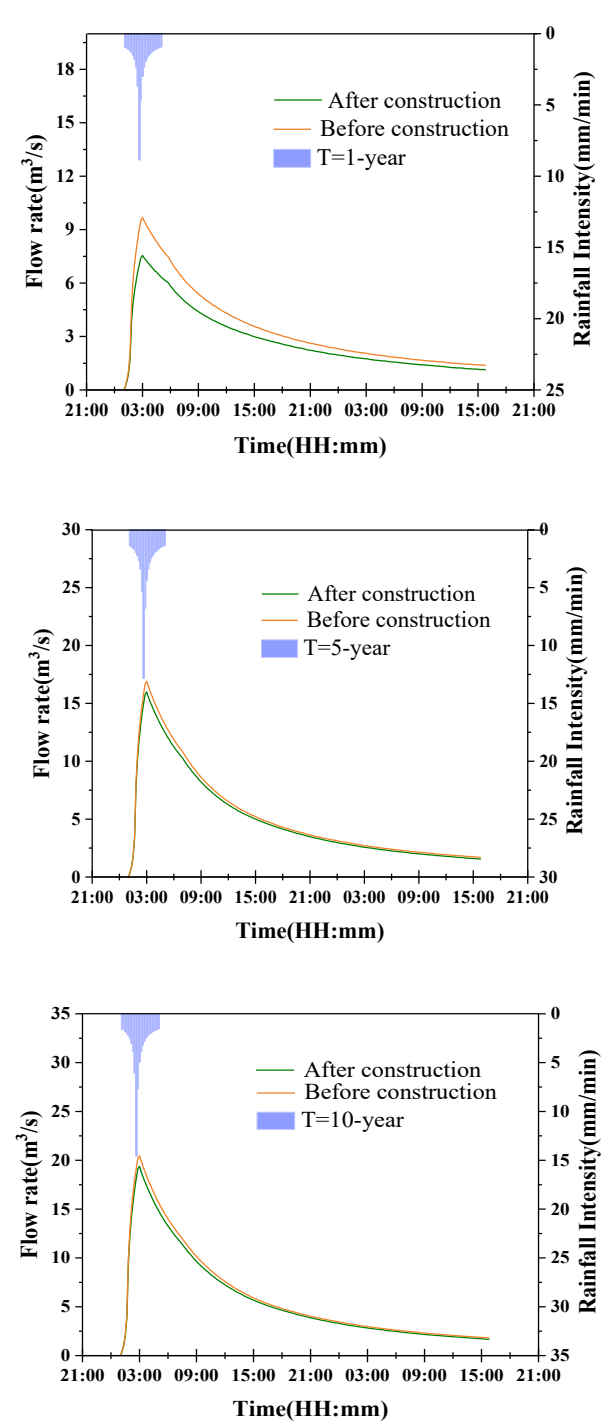

Figure 7. Comparison of runoff processes for different return periods after Sponge City construction.

\section{Drainage capacity of pipe networks}

The incidence of overflows and pipe overloading at nodes was analysed for the three design events and the results are shown in Tables 4 and 5. Taking the 1-year return period as an example, after construction of the Sponge City, the number of nodes with overflows was reduced from 13 to 6 and average overflow duration was reduced from 11.5 to 9.0 hours. Total overflow was reduced from 396.9 to $286.610^{6} \mathrm{~m}^{3}$, representing a reduction rate of $27.8 \%$. The number of nodes with pipe overloading was reduced from 15 to 8 (Table 5), a reduction rate of $46.7 \%$, and the average duration of full flow decreased from 9.9 to 7.3 hours. The reductions in overflow rates and durations and incidences of pipe overloading for the 5- and 10-year events were less marked, suggesting that the effects of the Sponge City interventions are most effective for the most frequent events and that the capacity of pipe networks remains insufficient for rarer events.

\begin{tabular}{|c|c|c|c|c|c|c|}
\hline \multicolumn{2}{|c|}{$\begin{array}{l}\text { Return } \\
\text { period } \\
\text { (years) }\end{array}$} & $\begin{array}{l}\text { No. of } \\
\text { nodes } \\
\text { with } \\
\text { over- }\end{array}$ & $\begin{array}{l}\text { Over- } \\
\text { flow } \\
\text { reduc- } \\
\text { tion } \\
\text { rate }\end{array}$ & $\begin{array}{c}\text { Average } \\
\text { over- } \\
\text { flow } \\
\text { dura- }\end{array}$ & $\begin{array}{l}\text { Total } \\
\text { over- } \\
\text { flow } \\
\left(10^{6} \mathrm{~m}^{3}\right)\end{array}$ & $\begin{array}{l}\text { Total } \\
\text { over- } \\
\text { flow } \\
\text { reduc- } \\
\text { tion }\end{array}$ \\
\hline \multirow{2}{*}{1} & Before & 13 & \multirow{2}{*}{53.9} & 11.5 & 396.9 & \multirow{2}{*}{27.8} \\
\hline & After & 6 & & 9.0 & 286.6 & \\
\hline \multirow{2}{*}{5} & Before & 33 & \multirow{2}{*}{18.2} & 23.0 & 3804.2 & \multirow{2}{*}{3.9} \\
\hline & After & 27 & & 25.2 & 3657.3 & \\
\hline \multirow{2}{*}{10} & Before & 33 & \multirow{2}{*}{3.0} & 32.5 & 4509.7 & \multirow{2}{*}{1.1} \\
\hline & After & 32 & & 33.6 & 4459.6 & \\
\hline
\end{tabular}

Table 4. Comparison of nodes overflows in different return periods after Sponge City construction.

\begin{tabular}{|c|c|c|c|c|}
\hline \multicolumn{2}{|c|}{$\begin{array}{c}\text { Return period } \\
\text { (years) }\end{array}$} & $\begin{array}{c}\text { Locations } \\
\text { with pipe } \\
\text { over- } \\
\text { loading }\end{array}$ & \multirow{2}{*}{$\begin{array}{c}\text { Overload } \\
\text { reduction } \\
\text { rate (\%) }\end{array}$} & $\begin{array}{c}\text { Average full } \\
\text { flow } \\
\text { duration (h) }\end{array}$ \\
\hline \multirow{2}{*}{1} & Before & 15 & \multirow{2}{*}{46.7} & 9.9 \\
\cline { 2 - 3 } \cline { 5 - 5 } & After & 8 & \multirow{2}{*}{20.6} & 7.3 \\
\hline \multirow{2}{*}{5} & Before & 34 & & 32.0 \\
\cline { 2 - 3 } & After & 27 & \multirow{2}{*}{3.0} & 25.4 \\
\hline \multirow{2}{*}{1} & Before & 34 & 32.5 \\
\cline { 2 - 3 } 0 & After & 33 & & 31.7 \\
\hline
\end{tabular}

Table 5. Comparison of pipe overloads in different return periods after Sponge City construction.

\section{Benefits of SuDS in the UK}

\subsection{Greenfield runoff estimation}

A key motivation for installing SuDS features in urban areas of the UK is the reduction of surface water flood risk. The CIRIA SuDS Manual (Woods Ballard et al., 2015) provides guidance on the planning, design, construction and maintenance of SuDS, together with details of supporting research. The design of a SuDS scheme for a greenfield or previously developed site requires an estimate of peak runoff rates and runoff volumes from the site in its greenfield state. However, estimates of greenfield runoff are usually derived from generalised methods such as those provided by the Flood Estimation Handbook (FEH: Institute of Hydrology, 1999), which are designed to estimate fluvial flood frequency and were developed from streamflow measurements at the small catchment scale, rather than runoff measurements at the plot scale. This introduces uncertainty into plot-scale runoff estimation, although recent research has reviewed related research and updated current guidance for the UK (Stewart et al., 2019).

There is a general lack of suitable data on greenfield runoff rates in the UK and relatively few experimental studies of the reduction in runoff rates that can be achieved through SuDS have been published. However, those studies that have considered the effectiveness of sustainable drainage support the conclusion that the maximum benefits are achieved in the most frequent 
events. For example, Vesuviano (2014) applied standard summer design storms of 10- and 100-year return period to an inner city green roof at field capacity built into a rainfall simulator. The green roof was found to achieve a delay between $50 \%$ of rainfall volume and $50 \%$ of runoff volume of 8 minutes for the 10-year storm event and 5 minutes for the 100-year storm.

In the USA, Holman-Dodds et al. (2003) undertook an evaluation of the hydrological benefits of infiltrationbased urban storm water management. They present a number of experiments using a hydrological model to compare three scenarios of development: pre-developed, traditional 'high impact' storm water management and 'low impact' infiltration-based management. The study demonstrates that the amount of reduction in storm runoff is sensitive to the magnitude of the rainfall event and soil texture and permeability, with low impact management having the greatest effects during the most frequent storm events. The low impact development was found to have little effect during the most extreme events unless the soil had a high infiltration capacity.

\subsection{SuDS case study}

In May 2019, members of the project team from China and the UK took part in a study visit to the Queen Caroline Estate in Hammersmith, West London. Here, a range of low-cost sustainable drainage solutions has been retrofitted within a social housing development dating from the mid-twentieth century. The project was implemented by Groundwork London in partnership with the London Borough of Hammersmith and Fulham as part of the Climate Proofing Landscapes project funded by the EU LIFE+ Programme. It aimed to demonstrate the role that urban housing estates can play in increasing the resilience of cities to climate change. A number of social housing sites were targeted in order to help reduce the environmental vulnerability of deprived communities. A variety of SuDS components have been installed on the Queen Caroline Estate to reduce the risk of surface water flooding, as well as to mitigate the urban heat island effect, improve biodiversity and create more sustainable communities.

The tour of the site identified how the sustainable drainage components have been integrated into the estate landscape, involving a range of spaces from roofs to pavements, car parks, roads and soft landscaped areas. Rain gardens were incorporated into paved areas and alongside roads to improve drainage, and vegetated channels, swales and small- to medium-sized basins were also introduced to manage runoff from roofs and paving. The main features have been designed to manage the 100year storm event. The University of East London is undertaking monitoring on the site to assess the performance of the SuDS components and the cooling effect of green roofs.

An important element of the whole programme has been community involvement and, before the project began, residents of the estate were engaged in pre-design conversations to identify specific problems with existing drainage and their priorities for improvements to the open space. Many residents wanted more colour in the landscape and, in response, biodiverse green roofs were planted with wildflower seeds and plugs installed on bin stores and pram sheds. Basins and adjacent landscaping include informal play features including bridges, mounds, logs, balance beams and boulders. Consultation has taken place throughout the project to balance various requirements such as the Council's aim to avoid significant changes to maintenance and the residents' concerns about antisocial behaviour. Informal play features such as bridges and mounds have been included in the detention basins and adjacent landscaping (Figure 8).

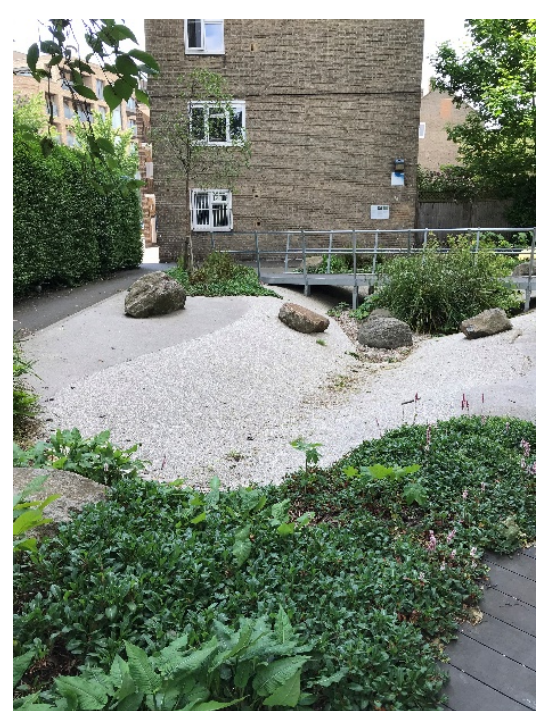

Figure 8. Low maintenance stony detention basin

The site visit confirmed the feasibility of retrofitting SuDS interventions and other green infrastructure into older developments and the wide range of benefits that the programme has brought to the local community. A case study of the Queen Caroline Estate giving further information is available on the SUSDRAIN website:

https://www.susdrain.org/case-

studies/case studies/queen caroline estate london.html

\section{Discussion and conclusions}

Increasing population, urbanisation and climate change mean that surface water flooding risk is increasing throughout the world. China experiences particular problems since an increasing proportion of its population live in large cities. The threat of surface water flooding is also increasingly recognised in smaller countries such as the UK, where widespread flooding in the summer of 2007 caused huge and lasting impacts on urban communities.

Two similar adaptation strategies are the Sponge City concept and the implementation of SuDS features, both of which can be used in new developments or retrofitted in existing urban areas. Both initiatives deliver improved infiltration and drainage in urban areas and are designed to have positive effects on water quantity (by reducing floods) and water quality (by reducing pollution), as well as enhancing amenity and biodiversity.

The case study of the impacts of Sponge City construction in Wuhan has demonstrated that peak flow 
rates and runoff volumes are reduced by an average of $40 \%$ across the study area and overflows and pipe overloading are also reduced. However, these effects are most obvious for relatively frequent storm events such as the 1-year return period event and sustainable drainage systems may only have a limited impact on more extreme events.

Importantly, working with natural process in both urban and rural settings not only increases resilience to extreme events but also brings multiple benefits to local communities by improving water quality, greening the local environment and promoting good health and wellbeing.

\section{Acknowledgements}

This project is funded by the UK-China Urban Flooding Research Impact Programme through the Royal Academy of Engineering under its remit as a Delivery Partner in the UK-China Newton Fund. The Project Team is grateful to staff from Groundwork London for arranging a tour of the SuDS features at Queen Caroline Estate, Hammersmith in May 2019.

\section{References}

1. Changjiang River Scientific Research Institute (CRSRI) (2019). Study on the effect of Sponge City building in Qingshan South Trunk Canal Demonstration Area, Wuhan. Unpublished project report, $21 \mathrm{pp}$.

2. Cheshmehzangi, A. (2016). China's New-Type Urbanisation Plan (NUP) and the foreseeing challenges for decarbonization of cities: A review. Energy Procedia 104: 146-152.

3. CIRIA (2019). B£ST (Benefits Estimation Tool). https://www.susdrain.org/resources/best.html

4. Dai, L., H.F.M.W. van Rijswick, P.P.J. Driessen and A.M. Keessen (2017). Governance of the Sponge City Programme in China with Wuhan as a case study. International Journal of Water Resources Development 34(4): 578-596.

5. Environment Agency (2009). Flooding in England: A National Assessment of Flood Risk. E.A., Bristol. https://www.gov.uk/government/publications/floodi ng-in-england-national-assessment-of-flood-risk

6. EPA (2016). Storm Water Management Model Fact Sheet. https://www.epa.gov/water-research/stormwater-management-model-swmm

7. Griffiths, J., F.K.S. Chan, M. Shao, F. Zhu and D.L. Higgitt (2019). Interpretation and application of Sponge City guidelines in China. Philosophical Transactions of the Royal Society A 378: 20190222.

8. Holman-Dodds, J.K., A.A. Bradley and K.W. Potter (2003). Evaluation of hydrologic benefits of infiltration based urban storm water management. Journal of the American Water Resources Association 39(1): 205-215.

9. Houston, D., A. Werritty, D. Bassett, A. Geddes, A. Hoolachan and M. McMillan (2011). Pluvial (rainrelated) flooding in urban areas: the invisible hazard. Joseph Rowntree Foundation.
10. Institute of Hydrology (1999). Flood Estimation Handbook (five volumes). UK Centre for Ecology \& Hydrology, Wallingford, UK.

11. IPCC (2014). Climate Change 2014 Synthesis Report.

12. Keifer, D.J. and H.H. Chu (1957). Synthetic Storm Pattern for Drainage Design. ASCE Journal of the Hydraulics Division 83 (HY4):1332.1-1332.25.

13. Kundzewicz, Z., B. Su, Y. Wang, J. Xia, J. Huang and T. Jiang (2019). Flood risk and its reduction in China. Advances in Water Resources 130: 37-45. https://doi.org/10.1016/j.advwatres.2019.05.020

14. Lashford, C., M. Rubinato, Y. Cai, J. Hou, S. Abolfathi, S. Coupe, S. Charlesworth, and S. Tait (2019). SuDS \& Sponge Cities: a comparative analysis of the implementation of pluvial flood management in the UK and China. Sustainability 11: 213. https://doi.org/10.3390/su11010213

15. Lenth, J. (2016). Practice and Reflections on the Ecological Infrastructure Construction in China. Landscape Architecture Frontiers 4 (5).

16. Marsh, T.J. (2008). A hydrological overview of the summer 2007 floods in England and Wales. Weather 63(9): 274-279. DOI: 10.1002/wea.305

17. Miller, J.D. and M. Hutchins (2017). The impacts of urbanisation and climate change on urban flooding and urban water quality: A review of the evidence concerning the United Kingdom. Journal of Hydrology: Regional Studies 12: 345-362. http://dx.doi.org/10.1016/j.ejrh.2017.06.006

18. Ministry of Housing and Urban-Rural Development (MOHURD) (2014). Technical guide for Sponge City construction: Construction of stormwater system in low-impact development (in Chinese).

19. Pitt, M. (2008). Floods Review.

https://webarchive.nationalarchives.gov.uk/2010081 2084907/http://archive.cabinetoffice.gov.uk/pittrevi ew//media/assets/www.cabinetoffice.gov.uk/floodi $\underline{\text { ng review/pitt review full\%20pdf.pdf }}$

20. Rudd, A.C, A.L. Kay, S.C. Wells, T. Aldridge, S.J. Cole, E.J. Kendon and E.J. Stewart (2019). Investigating potential future changes in surface water flooding hazard and impact. Hydrological Processes 34: 139-149.

https://doi.org/10.1002/hyp.13572

21. Stewart, E.J., D.S. Faulkner, G. Formetta, A.B. Griffin, T. Haxton, I. Prosdocimi, G. Vesuviano, A.R. Young (2019). Estimating flood peaks and hydrographs for small catchments. Report SC090031/R0, Joint Flood and Coastal Erosion Risk Management Research and Development Programme, Environment Agency, Bristol. Accepted October 2019.

22. UNDRR (2019). Global Assessment Report on Disaster Risk Reduction. United Nations Office for Disaster Risk Reduction (UNDRR), Geneva, Switzerland, 425pp.

23. Vesuviano, G. (2014) A Two-Stage Runoff Detention Model for a Green Roof. PhD thesis, University of Sheffield. 
24. Wheater, H.S. and E. Evans (2009). Land use, water management and future flood risk. Land Use Policy 26S: S251-264.

25. Woods Ballard, B., S. Wilson, H. Udale-Clarke, S. Illman, T. Scott, R. Ashley and R. Kellagher (2015). The SuDS Manual (C753). CIRIA, London.

26. World Bank (2012). Cities and Flooding: A Guide to Integrated Urban Flood Risk Management for the 21 st Century.

https://openknowledge.worldbank.org/handle/10986 2241. 